\title{
River terrace development in response to folding above active wedge thrusts in Houli, Central Taiwan
}

\author{
Yue-Gau Chen ${ }^{\text {a,* }}$, Jih-Hao Hung ${ }^{\mathrm{b}}$, Kuang-Yin Lai a, Yu-Nung N. Lin ${ }^{\text {a }}$, \\ Tarka Wilcox ${ }^{\mathrm{c}}$, Karl Mueller ${ }^{\mathrm{c}}$ \\ ${ }^{a}$ Department of Geosciences, National Taiwan University, Taipei, Taiwan, ROC \\ ${ }^{\mathrm{b}}$ Department of Earth Sciences, National Central University, Chungli, Taiwan, ROC \\ ${ }^{c}$ Department of Geological Sciences, University of Colorado, Boulder, CO 80309-0399, USA
}

Received 21 March 2004; received in revised form 18 September 2005; accepted 27 July 2006

\begin{abstract}
Folding at the leading edge of the western Taiwan thrust belt is well preserved by a flight of fluvial terraces at Houli. Strain in this region is driven by slip on the north trending Changhua and Sanyi blind wedge thrusts and occurs at the boundary between the Miaoli and Taichung neotectonic domains located respectively to the north and south. In the past century, two large historical earthquakes occurred in these two domains and produced surface ruptures within or close to the study area, indicating Houli is not only tectonically active but also critical for understanding the interaction between the neighboring active systems. Although abundant river terraces and their deformation by active structures have long been well known in the area, a kinematical model for this region has not yet been proposed. We have therefore remapped the geomorphic features using the $40 \mathrm{~m}$ DEM and aerial photos to identify often subtle structural features in order to separate the effects of folding interference produced by different active structural systems. Besides the Tuntzuchiao fault (TTCF), which generated the 1935 earthquake, two other active regional scale structural systems have been reported in Houli area: the Tiechanshan (TCS) anticline and the Changhua fault (CHF). Our results demonstrate a number of tectonic scarps and warped surfaces in association with the CHF and its coupled back thrust, indicating that the CHF system is active. In contrast, the flight of fluvial terraces distributed in the middle of the study area cannot be related to the growth of the TCS anticline. Instead, terraces here record growth of another smaller and previously unknown anticline, Yuehmei (tentatively named in this study and shortened to YM in the text). Although it has developed parallel to the TCS anticline, relevant seismic profiles show the YM anticline as a local drag-fold attached to the southern limb of the TCS anticline and restricted in the Houli area. Based on the above observation, the TCS anticline can be interpreted as becoming less active where strain is instead transferred to the more rapidly uplifting YM anticline. This structural switch may be the result of interference between the newly developed southern Taichung system and the preexisting TCS anticline.
\end{abstract}

(C) 2007 Elsevier Ltd. All rights reserved.

Keywords: River terrace; Geomorphic feature; Neotectonics; Taan river; Houli; Structural morphology

\section{Introduction}

Taiwan is tectonically active due to the on-going arc-continent collision that occurs in eastern Taiwan (Ho, 1986; Teng, 1990; Fig. 1a). The collision event created an accretionary prism composed of $\mathrm{N}-\mathrm{S}$ trending mountain ranges that

\footnotetext{
* Corresponding author. Tel.: +88622369 7648; fax: +886223636095.

E-mail address: ygchen@ccms.ntu.edu.tw (Y.-G. Chen).
}

emerged as the island of Taiwan. As implied by a thinskinned model of the mountain building, its deformation front is largely propagating westward (Suppe and Namson, 1979). As a result, deformed terraces and disrupted tablelands are widely distributed in the western foreland. It is in this foreland that the Houli region is located, an area well-known for well-developed flight of fluvial terraces and tablelands (Fig. 1b; Lin, 1957; Shih et al., 1983, 1984; Lai, 2002). As pointed out in a recent study with respect to neotectonics of Taiwan (Shyu et al., 2004), the Houli tableland is situated 
between the neotectonic domains of Miaoli and Taichung. The former domain is structurally characterized by successive folds propagating seaward from the western Foothills, but without any major thrust emerging at the surface (CPC, 1974; Suppe and Namson, 1979; Namson, 1981, 1982). The large 1935 Hsinchu-Taichung earthquake occurred in this domain and produced surface ruptures. One of the ruptures, the Tungtzuchiao fault (TTCF) cut NE to SW across the eastern Houli area and caused damage in infrastructure and loss of life (Fig. 1b). In contrast, the Taichung domain is composed of several thrust sheets bounded by major emergent thrusts (Chiu, 1971; CPC, 1982; Suppe, 1983). Here, the Chelungpu fault, the second one from the western front, was responsible for the 1999 Chi-Chi earthquake, which generated surface ruptures and severe damage (CGS, 1999; Rubin et al., 2001; Chen et al., 2002). These two characteristic structure systems meet in the Houli area creating a complicated set of deformed landforms (Shih et al., 1984; Yang, 1986). However, the structural geometry and tectonic behavior of this linkage zone remains unclear so far. To further unravel the history of this part of Taiwan, this study aims to understand the tectonics of the Houli region by (1) remapping geomorphic surfaces by consideration of tectonic influences instead of only by elevation; (2) recognizing tectonic scarps based on the inferred behavior of associated structures; and (3) reevaluating the behavior and evolution of the major active systems.

\section{Local geology}

As shown in Fig. 1b, the characteristic multi-fold system of the Miaoli block seems to terminate at the northern mar- gin of the study area. The imbricated thrust system to the south (i.e., Changhua/Chelungpu/Shuangtung) also shows a significant disruption when it reaches this area (Fig. 1b). Based on the 1/50,000 scale geological map, the study area is mainly covered by Pleistocene Toukoshan Formation (TKS Fm, in Fig. 2) and younger strata, i.e., the molasse gravel beds and later terrace deposits. Its western margin is bounded by the northern end of the Changhua fault (abbreviated as CHF), a west-vergent thrust trending $\mathrm{N} 40^{\circ} \mathrm{E}$. In association with this frontal thrust, a back-thrust (i.e., Tachiatung fault, abbreviated as TCTF) is developed parallel to and $1-2 \mathrm{~km}$ to the east of the CHF fault (Fig. 2). In the eastern part of the study area, another two faults have been previously reported. One is the Sanyi thrust fault (SYF), striking N-S, and identified by field and subsurface evidence (Meng, 1963; Chang, 1971; Hung, 1994; Fig. 2); it has uplifted hills on its eastern side that are mainly composed of Pre-Pleistocene strata. The second fault is the Tuntzuchiao fault (TTCF), a dextral strike-slip fault striking $\mathrm{N} 60^{\circ} \mathrm{E}$ (Fig. 2). It was identified from coseismic surface ruptures that were produced in the earthquake of 1935 , which abruptly started at the southern bank of the Taan river at the intersection with the N-S SYF and then extended southwestward across the Houli tableland towards the southern bank of the Tachia river (Fig. 2). The spatial relationship between the SYF and TTCF faults is not entirely understood. It is believed that the TTCF is linked to a decollement in the northern Miaoli system following pre-existing normal faults (Yang et al., 2004; Lin, 2005), and its northern segment (i.e., in the north of Houli) is still covered by the Sanyi wedge thrust fault. However,
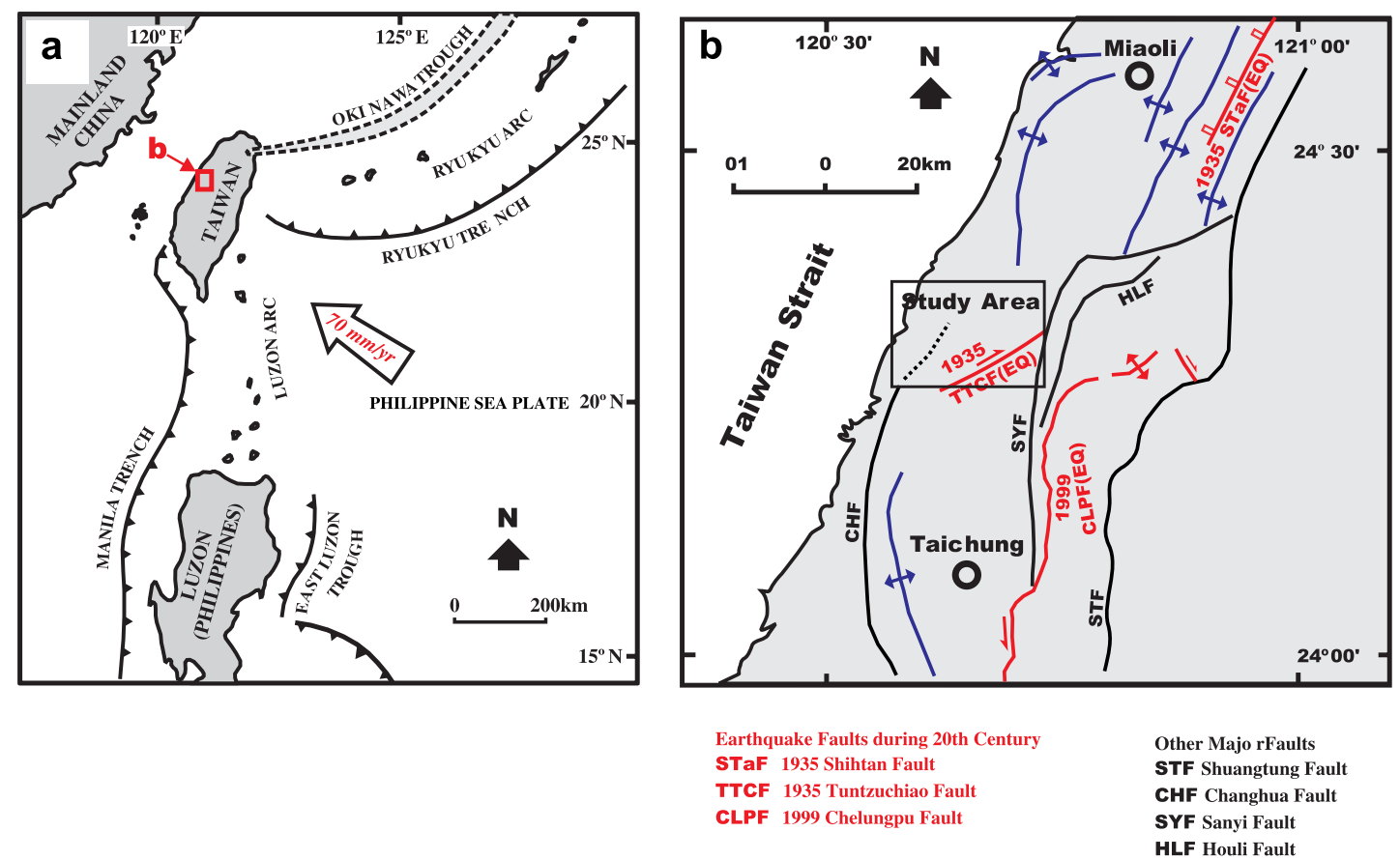

Fig. 1. (a) Current tectonic environments of Taiwan, where the arc-continent collision has occurred since late Miocene and is still on-going, based on the northwestward motion of the Philippine Sea plate with respect to the Chinese continental margin (Ho, 1986; Teng, 1990). (b) Map of western-central Taiwan showing major structures. The Miaoli block shows successive folds seaward from the western foothills and the Taichung block shows several thrust sheets bounded by three major thrusts, i.e., Changhua, Sanyi-Chelungpu, and Shungtung fault. The two characteristic structure systems merge in study area. 

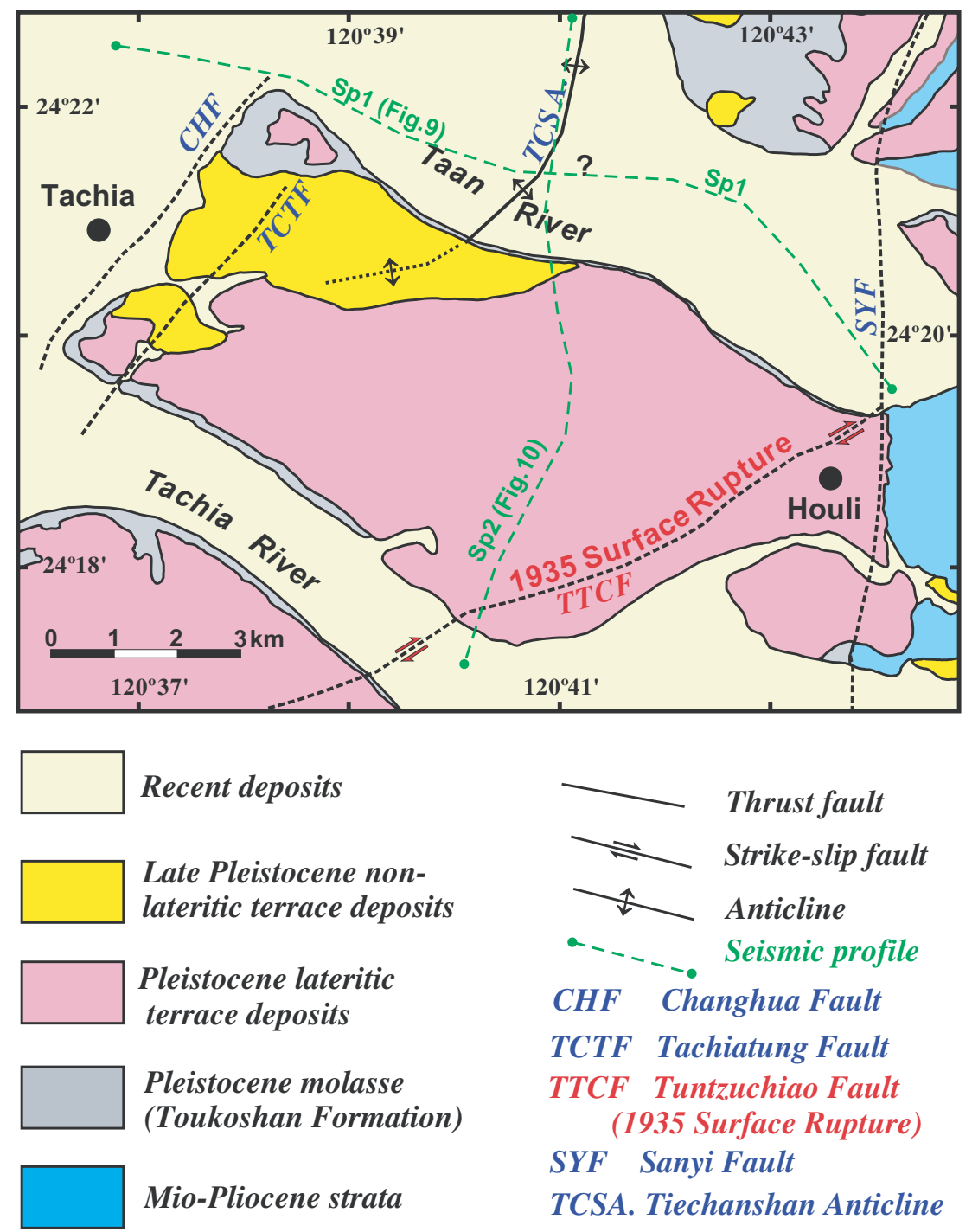

Recent deposits

\section{Late Pleistocene non-} lateritic terrace deposits

\section{Pleistocene lateritic terrace deposits}

Pleistocene molasse (Toukoshan Formation)

Mio-Pliocene strata

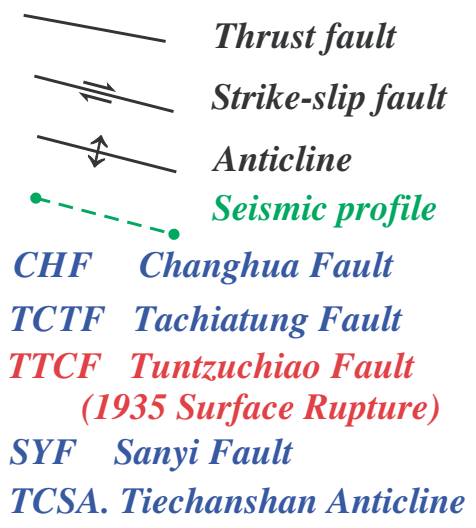

Fig. 2. The geologic map of the study area (CPC, 1982; Chang, 1994). The dashed-lines, sp1 and sp2, are locations of seismic profiles in Figs. 10 and 11 , respectively.

this thrust sheet has been reported as somewhat deformed by the recent action of the TTCF (Lin, 2005).

\section{Terrace compositions and ages}

Based on field observations, the composition of river terrace deposits in the Houli tableland can be generally divided into two units: the lower strata and upper covering fluvial deposits. The lower unit consists of a coarsening upward coastal fan-delta sequence with a thickness of over $200 \mathrm{~m}$ (Fig. 3). Within the sequence, sandy silt with intermittent tidal-influenced structures usually appears at its base, whereas massive alluvial cobbles become dominant elsewhere in the unit. Above the fan-delta sequence fluvial coarse sand overlies near the terrace surface (Fig. 3). The buried fan-delta sequence is regionally correlated to the Pleistocene TKS Formation based on lithology. As is common, such a fan-delta system is commonly found along the most active thrust front in the foreland of fold-and-thrust belt that constitutes western Taiwan. Here, the closest thrust fault mountainward is the SYF (Fig. 2). Since the terraces in the Houli region have been uplifted by the CHF and the SYF is no longer associated with fan-delta deposition, we believe the SYF might accommodate less strain more recently. Alternatively, all the terraces developed in the study area expose a thin capping sequence of fluvial deposits that unconformably overlie the top of fan-delta sequence (Fig. 4). Except for the lowest terrace I, the upper few meters of terrace deposits have a well-developed lateritic soil (Fig. 5). In Taiwan, lateritic terraces and tablelands have long been recognized as being relatively older than non-lateritic ones (Chen and Liu, 1991). With the exception of some specified cases, lateritic terraces are generally developed in Pleistocene deposits and non-lateritic terraces in Holocene deposits (Ota et al., 2006). Two drift-wood samples collected within the lower sedimentary sequence during the field investigation of this study were dated by conventional radiocarbon assay and yielded infinite ages $(>50,000$ 


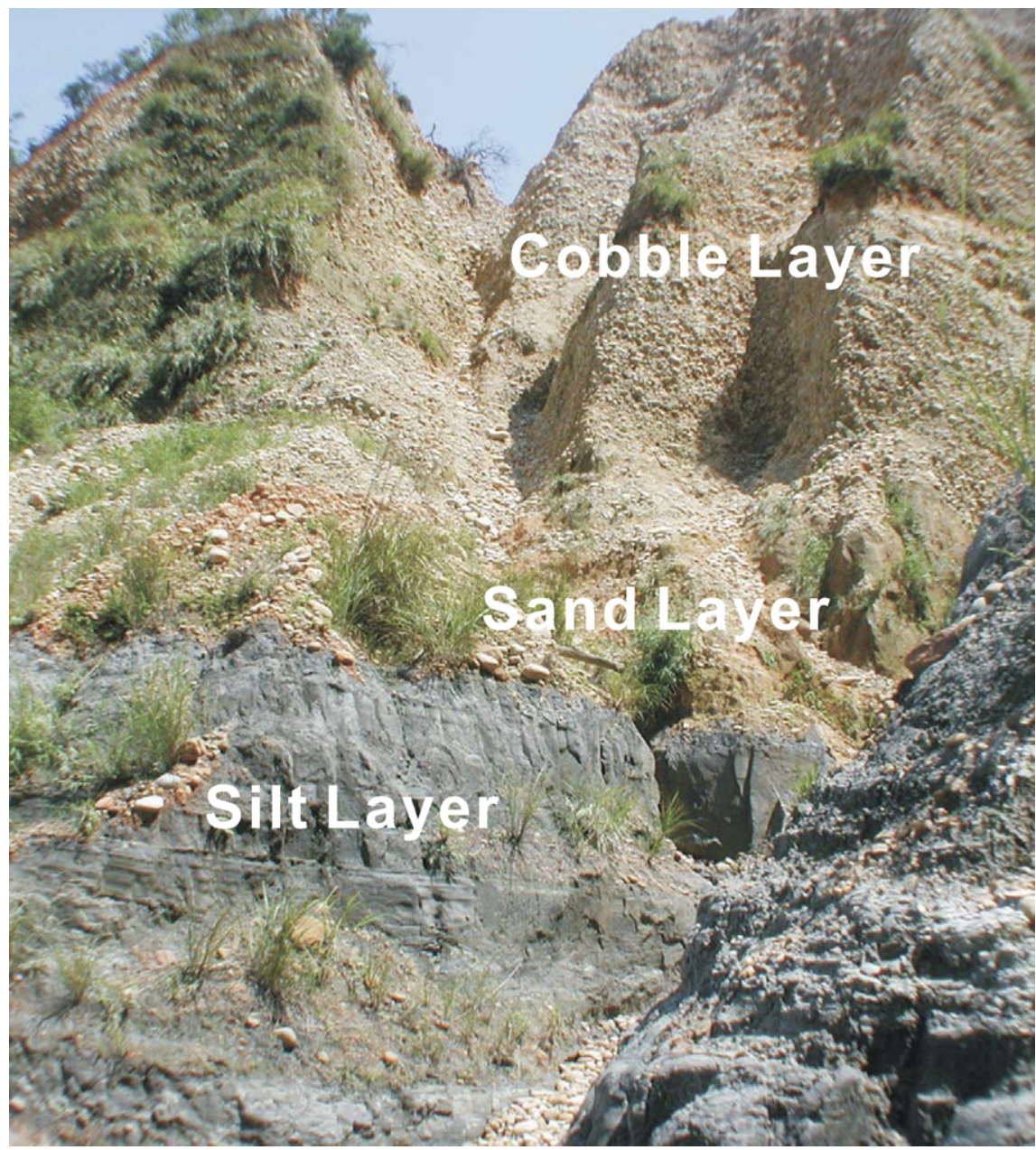

Fig. 3. Photo showing the lower unit of the terraces showing of a coarsening upward fan-delta sequence with thickness of over $200 \mathrm{~m}$. Such a fan-delta system is commonly found along the most active thrust front in the foreland of fold-and-thrust belt.

yrBP). Accordingly, Houli terraces may record a longer neotectonic history that begins in the late Pleistocene.

\section{Mapped terraces}

Using aerial photos and digital elevation model (DEM, resolution $40 \mathrm{~m}$ in grid), we remapped the terraces and their surface deformation including the antiforms, tilts, and tectonic scarps (Fig. 6). The lowest and highest terraces are distributed in $65-135 \mathrm{~m}$ and $165-260 \mathrm{~m}$, respectively, in elevation. In general, the higher level shows the larger covering elevation, implying cumulative deformation. There are 12 morphological steps presented in this study (I-XII in Figs. 6 and 7), which is a different interpretation to the previous studies (Shih et al., 1983, 1984; Yang, 1986; Lai, 2002) because we reconsider the tectonic influences such as warping and folding rather than simply elevation. For instance, the highest level was previously mapped into two surfaces due to the obvious elevation difference. In this paper, we regroup them together as one surface formed at the same time but subsequently deformed by anticlinal folding and separated by a monoclinal scarp. Terraces distributed in the central study area are mainly distributed ENE-SSW with their shape elongated upstream towards the modern Taan river, suggesting the possible sediment source was the paleoTaan river, whose course was governed by an active structure oriented ENE-SSW in Houli area. The tilted and deformed terraces allow us to define another anticline located in the southern limb of the preexisting geologic TCS anticline. We tentatively call it the Yuehmei (YM) anticline, a structure whose growth has controlled the northward development of mapped terraces (Fig. 6). The TCS anticline does not appear to be very active since its axis is roughly located within a topographic low and its southern end has been truncated by the CHF system (Fig. 6). Nevertheless, we think it is presently a relatively inactive structure, because it is associated with minor but detectable tilts on the terraces (Fig. 8A and B). Towards the western margin of the study area, all westernmost extensions of the terraces described above are further disrupted by fault scarps generated by the CHF system, showing complicated features (Fig. 8C-F). Except for a small northern butte, which is correlated with terrace XII in the southern part of the study area (Fig. 6), the others were developed as a northward advancing propagation order as in 


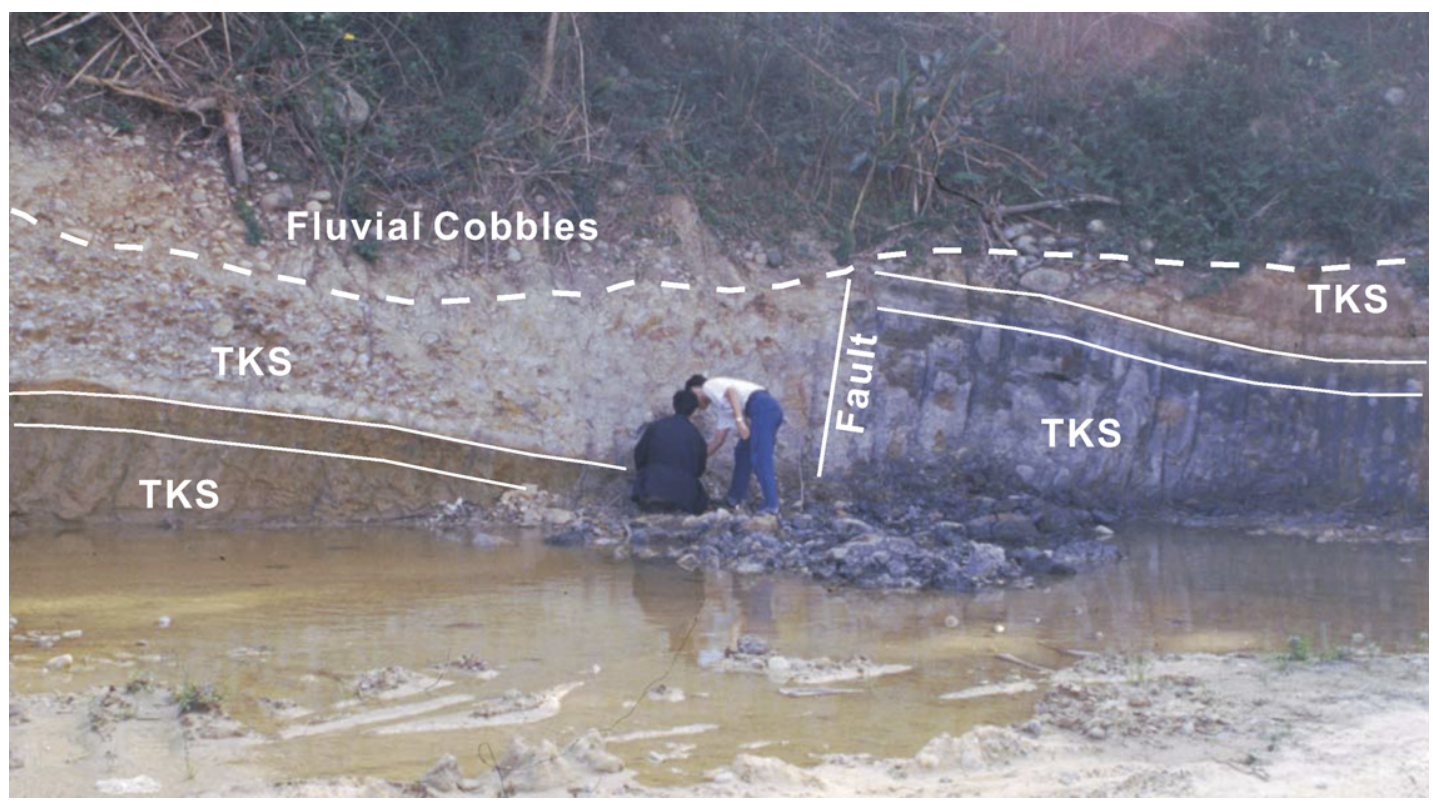

Fig. 4. Photo of the outcrop showing fluvial cobbles which are capped unconformably on the TKS Formation. The dashed-line shows the unconformity between the fluvial cobbles and TKS Formation. Solid line shows the bedding of the TKS Formation. The small fault zone is shown as white bar.

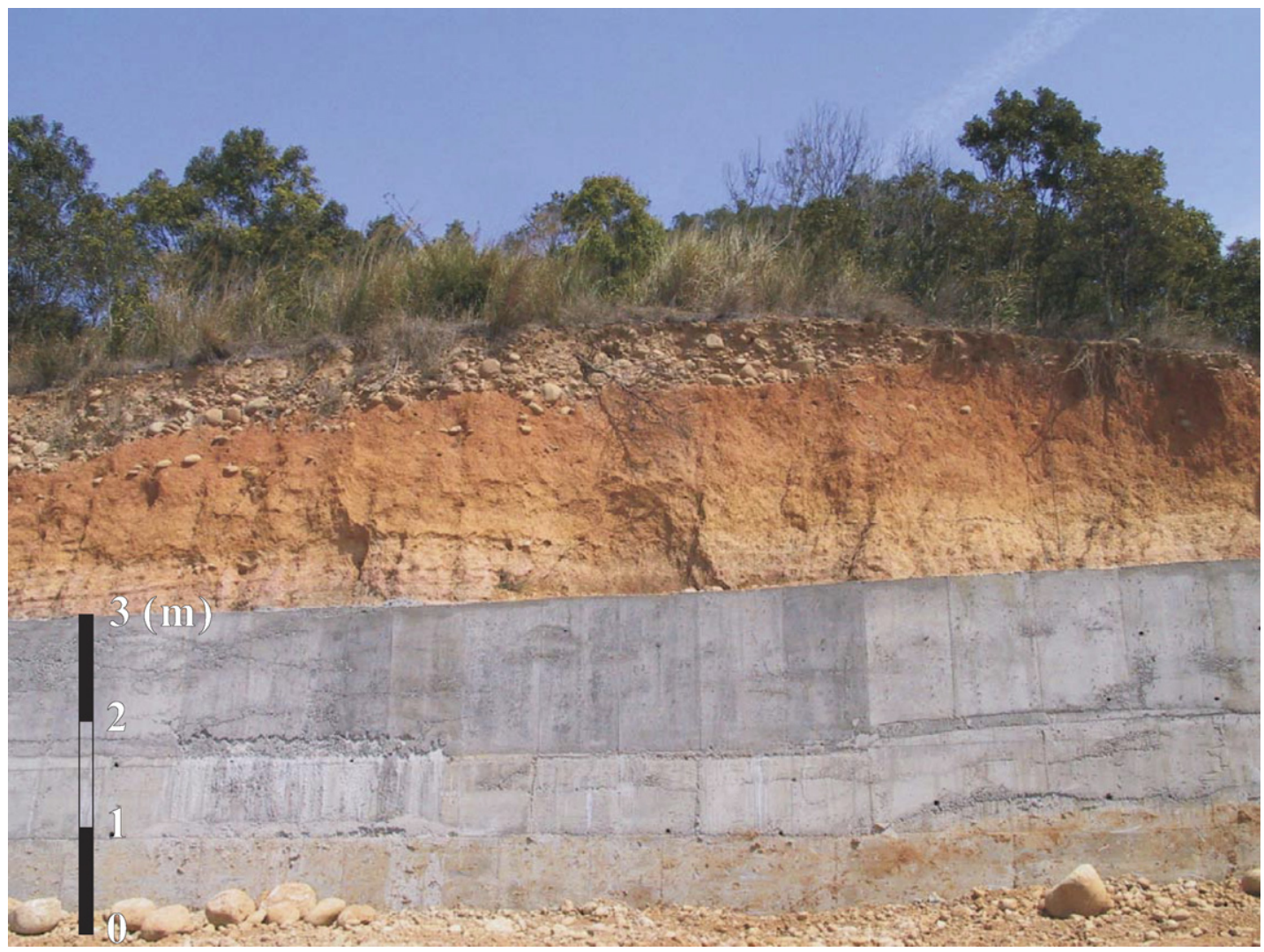

Fig. 5. Photo showing the top laterite of a few meters in thickness, which is widely distributed on almost all terraces except for the lowest terrace I.

the same manner as their eastern counterparts. The terraces along the southern part of the CHF, close to the Tachia river show tighter $\mathrm{N}-\mathrm{S}$ antiforms which gradually disappear to the north (Figs. 6 and 7). The detailed interactions of multiple active structures will be discussed in the later text.

\section{Tectonic and non-tectonic scarps}

The tectonic scarps presented in this study include both fold and fault scarps related to active structures. Small foldscarps are also considered in mapping tectonic scarps. 


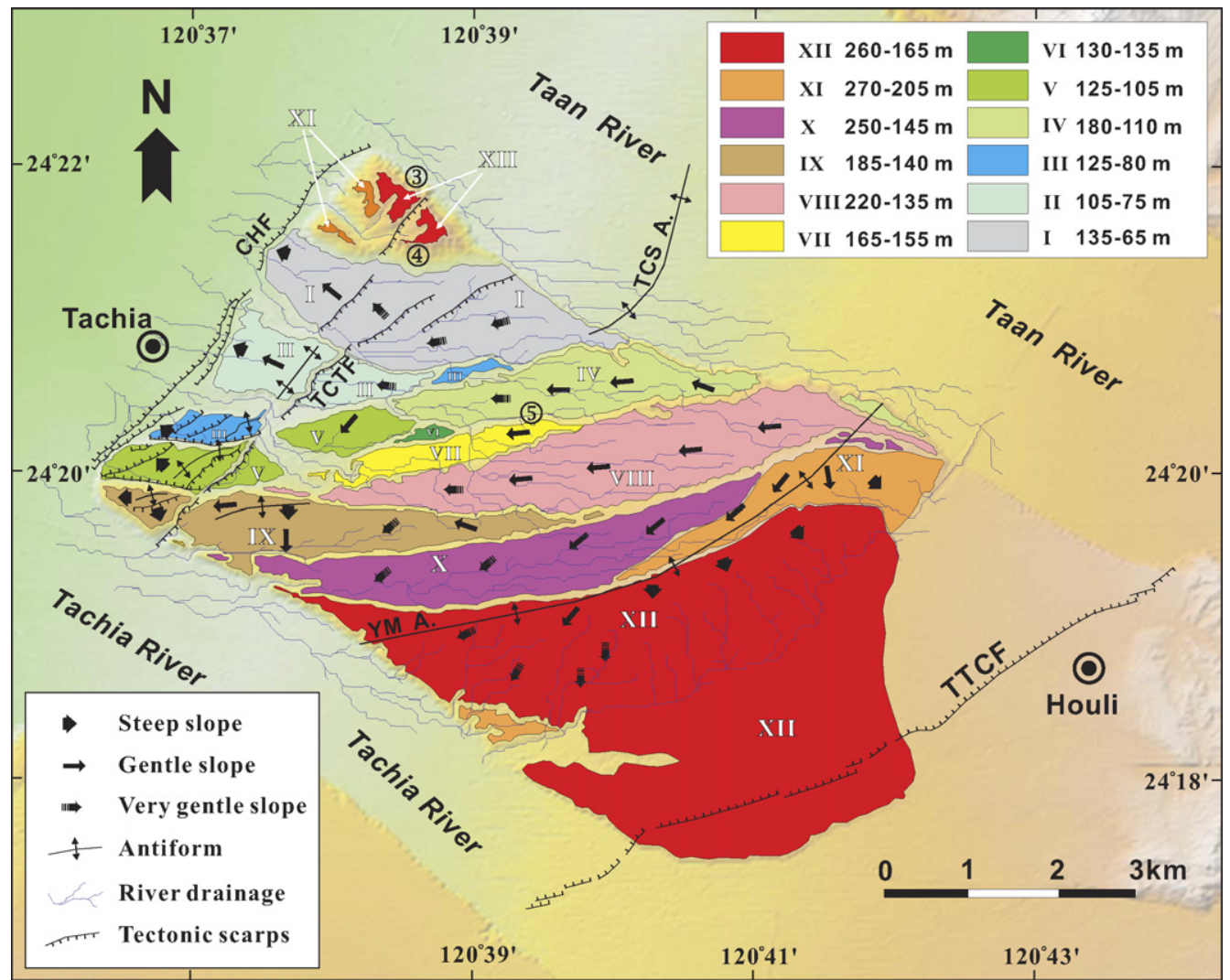

Fig. 6. Terrace map and their associated surface deformation including antiforms, tilts, and scarps. The tilted and deformed terraces surface allow us to define another anticline (YM A.) located to the southeast of the southern tip of preexisting geologic anticline (TCS A.). (3), (4), and (5) represent the locations of Figs. 3-5.

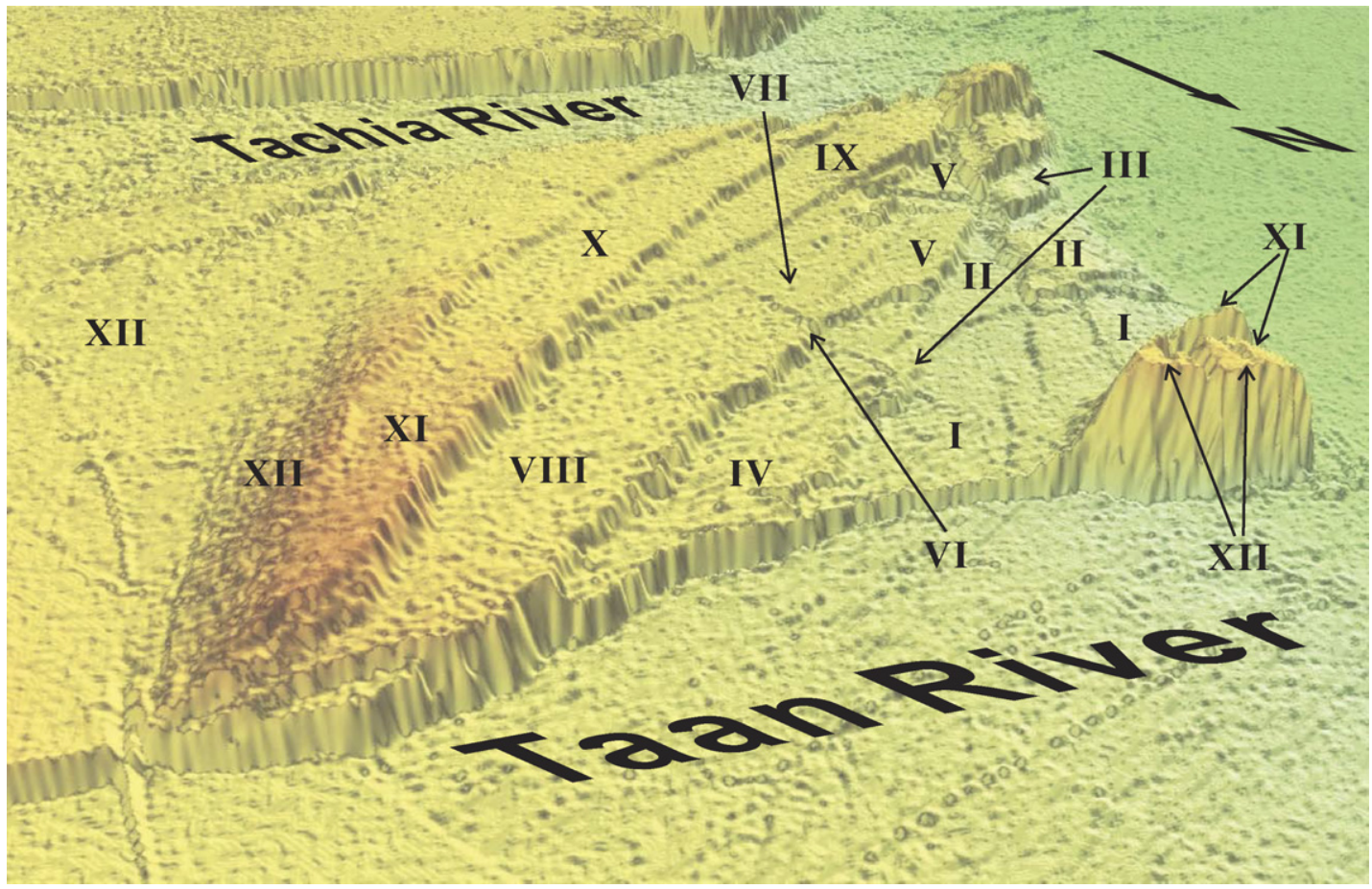

Fig. 7. 3D scene showing the topography of the study area and numbers showing different terraces corresponding to Fig. 6. (vertical exaggeration $5 \times$ ).

Scarps found in the central part of the study area are mostly terrace risers only, though their development is obviously related to the growth of YM anticline as dis- cussed above (Fig. 6). The bordering E-W scarps located in the north and south of the study area along the modern Taan and Tachia rivers are both regarded as risers formed 

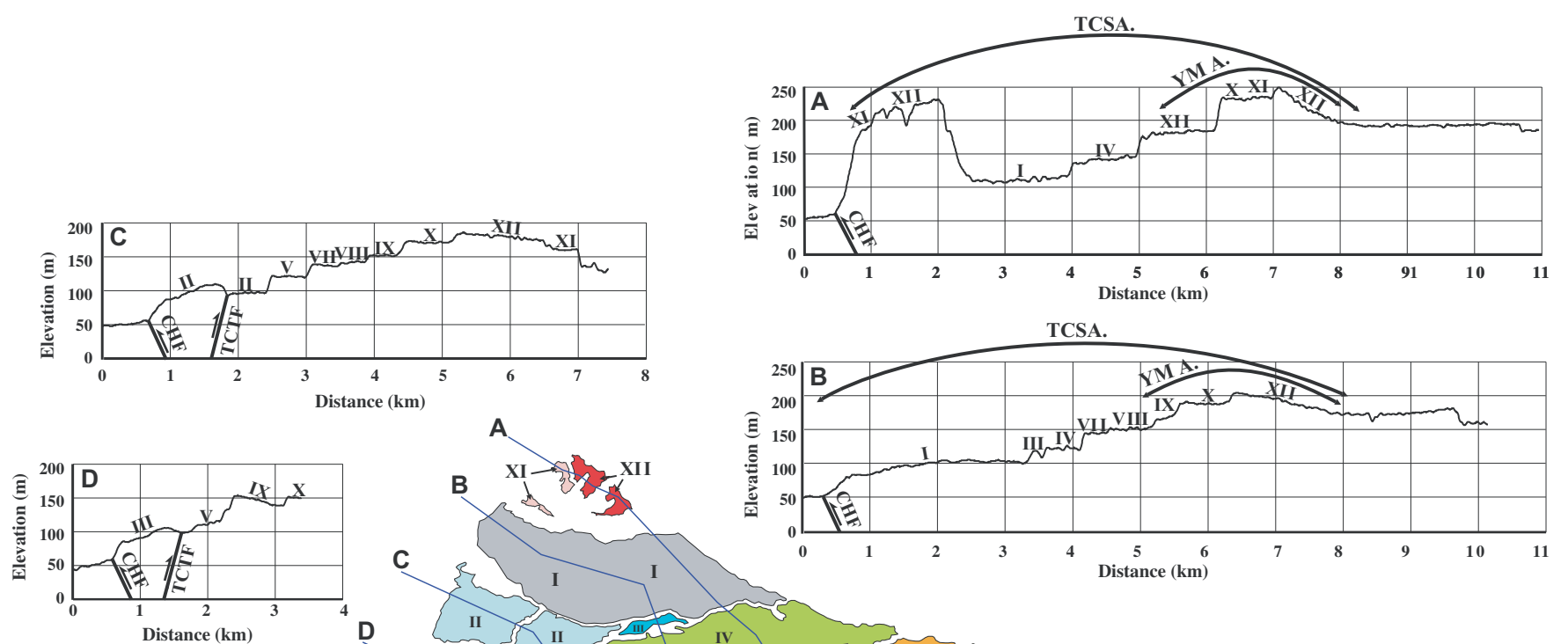

A
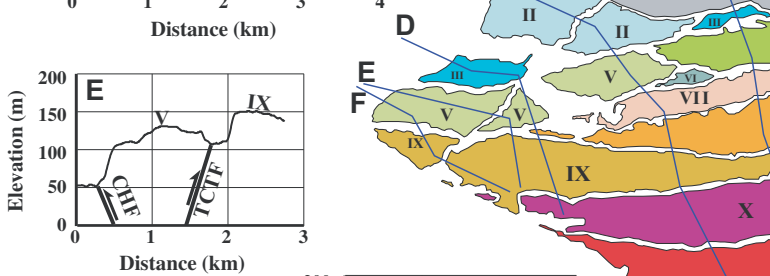

B
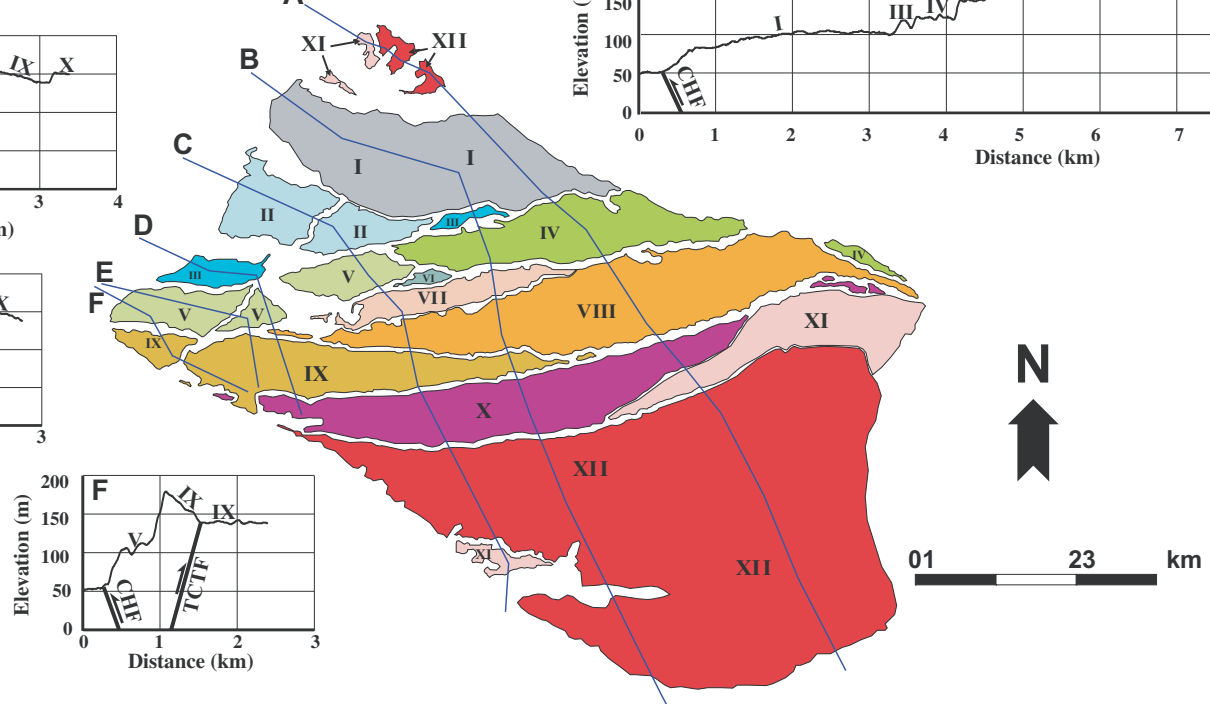

Fig. 8. Topographic profiles showing significant deformation on the terraces. The YM anticline governs the terrace deformation in the left-lower corner of the figure (profiles $\mathrm{C}-\mathrm{F}$ ). On the other hand, TCS anticline also provides minor but detectable tilts on the terraces; however, from the eroded topography it appears to be less active (A and B). To the western margin of the study area, terraces are further deformed by another active system, CHF system, showing complicated features $(\mathrm{C}-\mathrm{F})$.

by recent fluvial erosion. In the southeast, the 1935 surface ruptures remain distinct in several places (Fig. 6). The tectonic scarps are mostly concentrated in the west of the study area, where scarps are obviously developed by the action of the paired thrust and back-thrust system, the CHF/TCTF (Fig. 8C-F). The characteristics of tectonic scarps vary from south to north. In the south, distinct multiple fault scarps are formed in response to both frontal and back thrusts. To the north, the multiple scarps of the CHF become simpler, but the major scarp associated with the TCTF back thrust splays into a number of minor ones (Figs. 6 and 7). We believe some of the tectonic scarps are formed by slip along bedding by flexure-slip and created by anticlinal folding. As illustrated in Fig. 7, N-S trending tectonic scarps are somewhat segmented by several E-W short scarps. Since those scarps are all western extensions of the terrace risers from their eastern counterparts, we interpret them as being non-tectonic in origin.

\section{Surface deflection points}

Under the assumption that terrace surfaces were formed as continuous features at the same time, axial sur- faces mark the location of antiforms and synforms that can be related to subsurface structures defined by seismic reflection profiles. Fig. 9 illustrates the locations of axial surfaces where they cross the terraces (profiles in Fig. 9). On seven out of 12 terraces we found clear deflection points interpreted as either anticlinal or synclinal axial surfaces. Since the long axis of the terraces extends roughly parallel to the axis YM anticline, the resulting points can only be identified in highly exaggerated profiles. However, the length of these profiles is much greater than those drawn perpendicular to structures in this region and hence more fully capture fold geometry in spite of their much greater obliquity relative to fold trends. Results of our axial surface mapping indicate the presence of two antiformal axial surfaces located in the east and west of the study area, while an intervening synclinal axial surface is present between the two anticlines. We interpret the eastern anticlinal axial surface as the southern extension of the TCS anticline, while the western antiform is interpreted as being related to the TCTF back thrust. It is worth noting that the plunging nature of the folds contributes to uncertainty in locating axial surfaces associated with their development. 

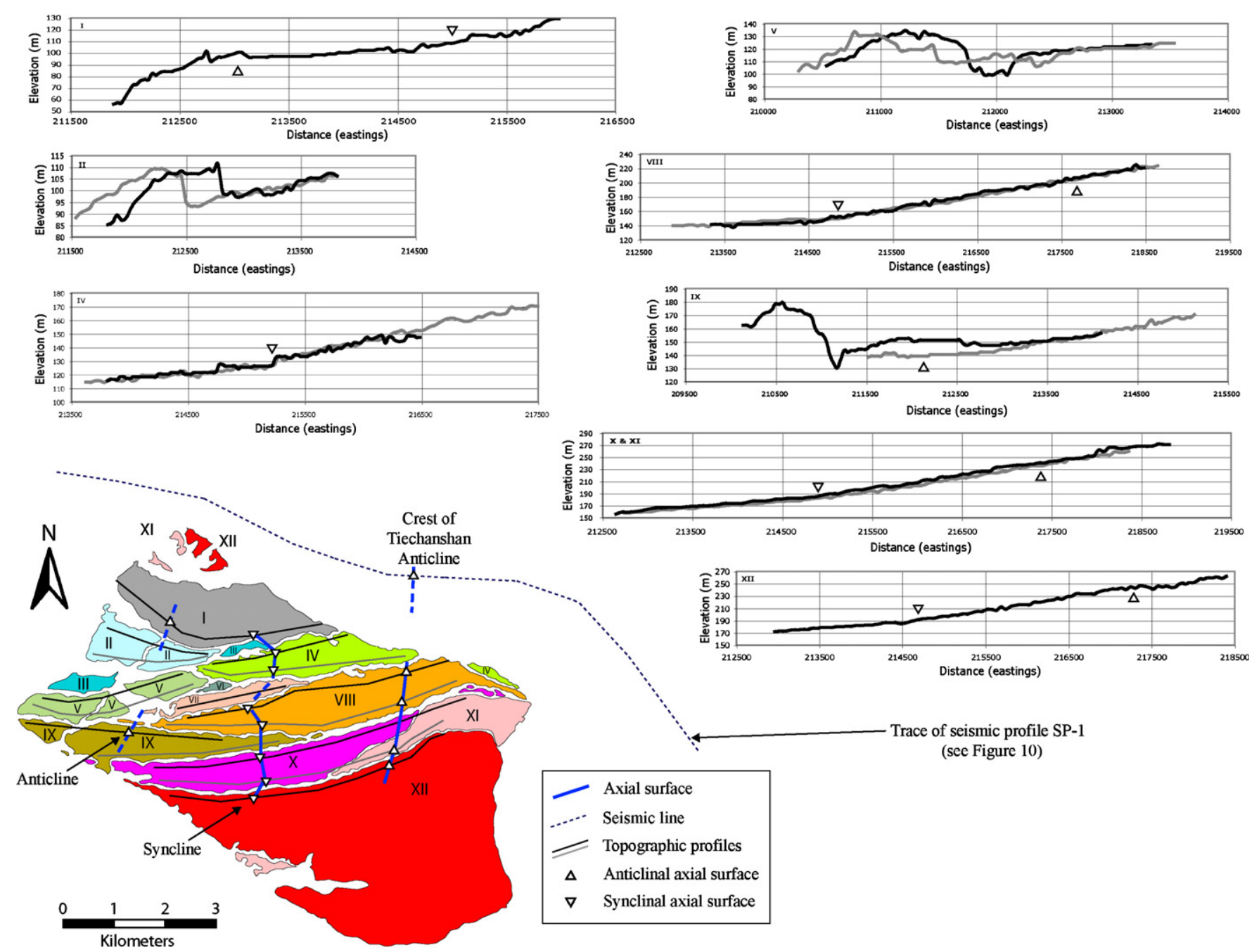

Fig. 9. Longitudinal profiles on the terraces show both concave upward and downward features that we interpret as anticlinal and synclinal axial surfaces related to changes in thrust ramp geometry at depth. Triangular symbols define the deflection points, located by projecting fold limbs. In the left lower corner, the map shows the profile locations and the distribution of the deflection points identified from the profiles.

\section{Discussion}

\subsection{Newly developed Tuntzuchiao fault}

Based on geomorphic features, three major active structures exist in the study area. The eastern one is the TTCF, which ruptured the surface in the 1935 earthquake. According to the post earthquake field observation in 1936 (Otuka, 1936), it is a dextral fault. However, almost no relevant geomorphic feature has been found to support it having a long active history except for the coseismic deformation produced by the 1935 event. Since it cuts through terrace XII, the oldest lateritic terrace, it ought to have accumulated a significant offset along both of the southern and northern edges if it indeed has a long active history. However, there is no detectable dextral offset along both edges, suggesting the TTCF may be a newly initiated fault, or one with an extremely long earthquake recurrence.

\subsection{Active Yuehmei anticline and less active Tiechanshan anticline}

The second active structure is the anticline system oriented ENE-SSW in the central part of the study area. It is evident that the southern extension of the TCS anticline plunges as defined by subsurface seismic data and abruptly changes strike from N-S to ENE-SSW as it approaches the Houli area (Fig. 2). According to the terrace deformation evidence presented in this study, the TCS anticline system here is no longer dominated by only one major axis as in the north (Fig. 10). A drag-fold, the YM anticline, has been developed on the southern limb of the TCS anticline to the south of Taan river (Fig. 11). Based on our map of terraces and structures that deform them, the master anticline does show recent deformation but to a degree much less than that defined on the YM anticline drag-fold. In particular, the topographic high matches with the YM fold axis rather than the TCS. Since the drag-fold apparently grows more 


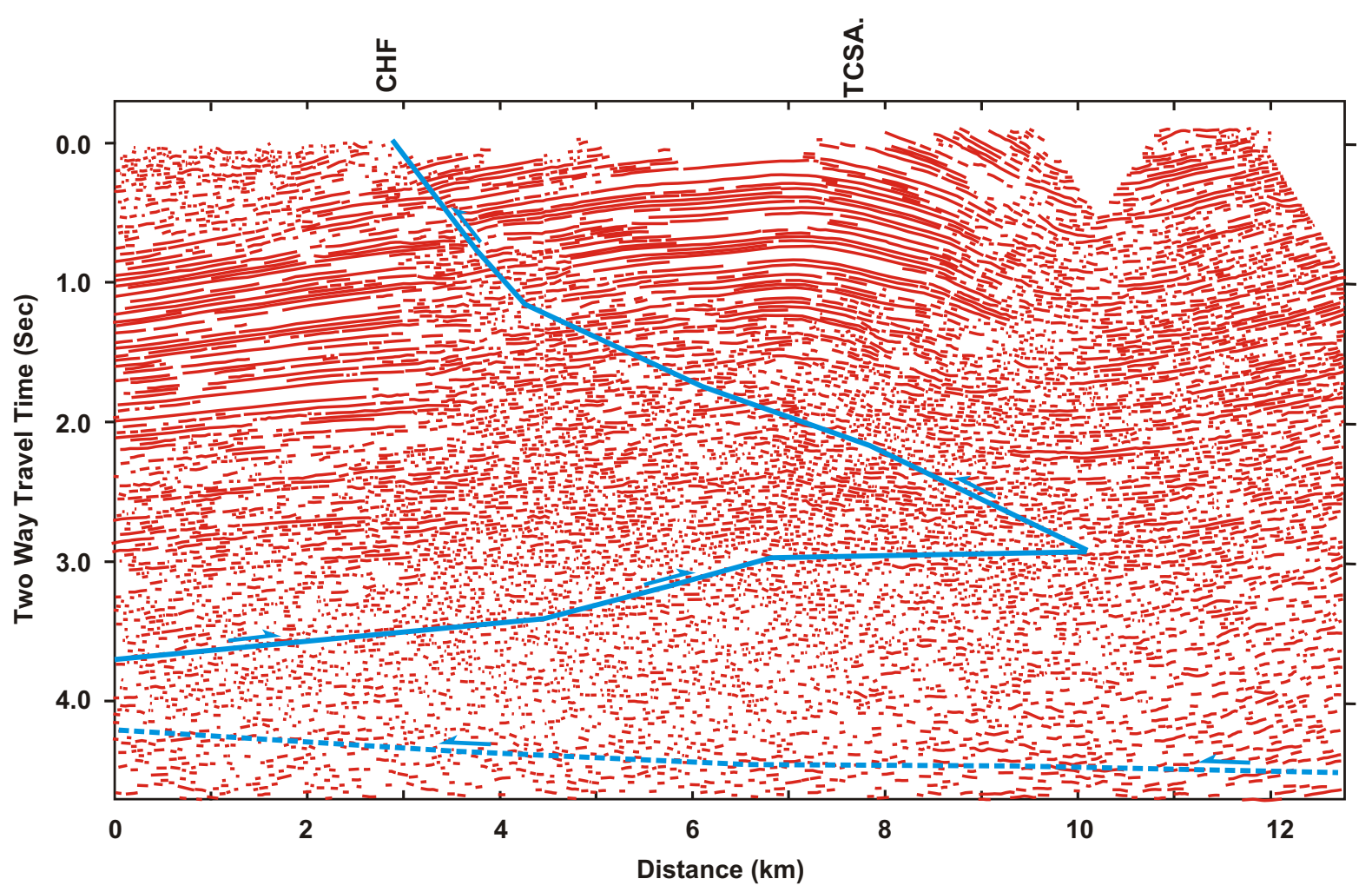

Fig. 10. Structural interpretation of seismic reflection profile sp1 (Hsu, 2001) of Fig. 2. The section crossing the north of the study area shows TCS anticline and CHF. This E-W profile across the Taan River shows the TCS anticline system dominates the deformation in the subsurface strata with only one major axis and the $\mathrm{CHF}$ in the western side.

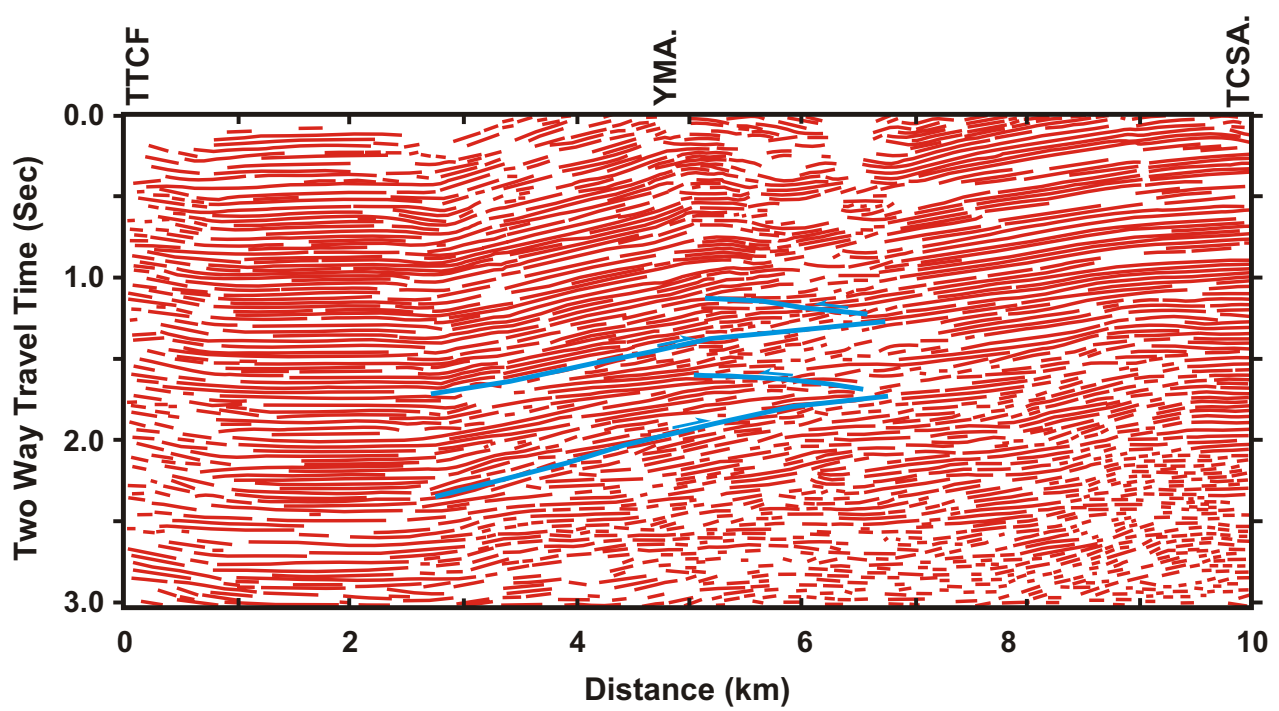

Fig. 11. Structural interpretation of seismic reflection profile sp2 (Chen and Su, 2002) of Fig. 2. A N-S profile across the terraces showing the YM anticline has been developed due to shortening occurring on the southern limb of TCS anticline south of the Taan river. In response to the shortening many small bedding truncations occur above the major detachment which is not shown because of low resolution in the profile.

rapidly than the master structure, we suggest that the development of YM is probably not caused by the growth of TCS anticline. Instead, it may be a product of contraction associated with strain transfer across the Taichung domain in the south. Since the TTCF system acts as a tear fault and is a dextral strike-slip fault trending the same as the fold axis of YM anticline, we argue that the new TTCF may be linked or related to the growth of the YM anticline.

\subsection{The role of the Tiechanshan anticline in the development of terraces}

According to the above discussion, the TCS anticline does not seem to play a major role in terraces of Houli. However, it should have been a key structure earlier in its history, as the course of the paleo-Taan river was restricted to the southern limb of the TCS fold until the YM anticline 
started growing. Otherwise, the Taan river would not be turned southwestward into the Houli tableland. Thereafter, the YM anticline became more active and the paleo-Taan river migrated northward, depositing sediments that comprise the Houli terraces. If the TCS fold did not initially form an obstacle to direct the paleo-Taan river into the Houli tableland, the subsequent terraces would not have been developed.

\subsection{Interfered Changhua system}

The third active system is the CHF and its associated subsidiary structures, including the back-thrust Tachiatung fault (Fig. 2). Since no evidence of the CHF is found to the north of the Taan river, Houli is likely to be the northernmost termination of the CHF, which is a dominant structure in the Taichung area in the south (Fig. 1). Here, the CHF interacts with the TCS and YM structures, successively disrupting the terraces from oldest to youngest, also reflecting a long active history during the late Quaternary. Apparent segmentations by E-W short scarps are however interpreted as terrace risers due to evident continuity with their eastern counterparts. The variations of scarp lines, geometries, and antiforms have resulted from interaction between the YM and TCS anticlines. In the southern part of the study area, immediately north of Tachia river, anticlinal folding and multiple scarps have resulted from interactions between the CHF and the active YM anticline. Moving northward, the CHF system interacts with the less active TCS anticline, producing an indistinct back thrust scarp instead of anticlinal folding.

\subsection{River piracy and implication on faulting}

In the late Pleistocene Houli terraces were abandoned by river piracy that captured the upper reach of the E-W Taan river to flow WNW as it does today. This implies that when the TCS anticline became less active piracy occurred in order to enable small drainages north of Houli to incise the hinterland hills and reach the valley of paleo-Taan river. The highest butte located in the northernmost of the study area is probably a relict hill remaining after the latest phase of river erosion. This explanation is consistent with the geomorphic observation that initially TCS was active, and forced the Taan river westward into Houli tableland. As the YM became active, the uplift on the TCS decreased, and the Taan river channel migrated northwards to its present position in response to uplift on the YM fold.

\section{Conclusions}

Based on deformation inferred from geomorphic features in the Houli area, we discovered the previously unmapped YM anticline. It could be interpreted as a dragfold attached to the southern limb of the TCS anticline; however, we interpret it to form due to local contraction associated with strain transfer across large segmented thrust systems at the leading edge of the Taiwan thrust belt. Based on its orientation and location, the TTCF system is interpreted to be linked with the YM anticline. The TTCF is an active fault that was recognized in 1935 from coseismic surface ruptures. Prior to the growth of the YM, the TCS was a topographic high which formed an obstacle to the paleo-Taan river, which flowed westwards along its southern limb. Thereafter, we argue the TCS slowed its growth rate and the YM started to develop. The paleoTaan river migrated northward following the growth of northern limb of the YM and formed a flight of river terraces in the rising southern bank. Since then, the TCS was no longer rapidly growing and small drainage courses to the northwest of Houli were able to incise upstream and capture the upper paleo-Taan river. As a consequence, the Houli terraces were abandoned and incised at their margins by the present-day Taan and Tachia rivers at the northern and southern margins of the tableland. In the western part of the study area, the CHF system interferes with the western extension of the TCS and YM structures, producing various geomorphic features. Except for the clear fault scarps associated with both the master and back thrusts, variations are controlled by the structural morphology of the TCS and YM anticlines.

\section{Acknowledgments}

We thank both our Taiwanese and western colleagues who have shared their thoughts during discussions in the field at Houli and at professional meetings. This project is financially supported by National Science Council and Central Geological Survey of Taiwan under grant numbers: NSC90-2119-M-002-009, NSC91-2119-M-002-024 and CGS5226902000-03-93-01.

\section{References}

Chang, S.L., 1971. Subsurface geologic study of the Taichung basin, Taiwan. Petroleum Geology of Taiwan 8, 21-45.

Chang, H.C., 1994. The geologic map of Tachia and explanatory text, scale 1:50000, published by Central Geological Survey, Taiwan, ROC.

CGS, 1999. Investigation report of 921 earthquake geology and Map of Surface Ruptures along the Chelungpu Fault during the 1999 Chi-Chi Earthquake. Central Geological Survey, Ministry of Economic Affairs, Taiwan, Republic of China (in Chinese).

Chen, Y.G., Liu, T.K., 1991. Radiocarbon dates of river terraces along the lower Tahanchi, northern Taiwan: Their tectonic and geomorphic implications. Proceedings of the Geological Society of China 34 (4), 337-347.

Chen, T.S., Su, F.C., 2002. Structure style of northern Changhua fault. Abstract volume of conference on Earth System Sciences. National Central University, Taiwan, pp. G133-G142.

Chen, Y.G., Chen, W.S., Wang, Y., Lo, P.W., Lee, J.C., Liu, T.K., 2002. Geormorphic evidence for prior earthquakes: Lessons from the 1999 Chichi earthquake in central Taiwan. Geology 30 (2), 171-174.

Chinese Petroleum Corporation (CPC), 1974. The geological map of Miaoli. Taiwan Petroleum Exploration Division Publication, Chinese Petroleum Corporation, Taiwan, ROC, scale 1:100,000.

Chinese Petroleum Corporation (CPC), 1982. The geological map of Taichung. Taiwan Petroleum Exploration Division Publication, Chinese Petroleum Corporation, Taiwan, ROC, scale 1:100,000. 
Chiu, H.T., 1971. Fold in the northern Half of Western Taiwan. Petroleum Geology of Taiwan 8, 7-19.

Ho, C.S., 1986. Geodynamics of the Eurasia-Philippine Sea plate boundary. Tectonophysics $125,1-16$.

Hsu, C.Y., Chung, K.C., 2001. Oil and Gas reservoir potential of the Huoyenshan structure, Mioali, Taiwan. Internal Report of Exploration Division, Chinese Petroleum Corp., Taiwan Petroleum Exploration Division.

Hung, J.H., 1994. Analysis of deformation fabrics in the Sani thrust sheet and the Chuhuangkeng anticline of western Taiwan. Petroleum Geology of Taiwan 29, 105-126.

Lai, K.Y., 2002. Geomorphic features and active structures: cases of Hsinshe and Houli area, central Taiwan. MS thesis, Institute of Geosciences, National Taiwan University, 79pp.

Lin, C.C., 1957. Geomorphology of Taiwan, published by Literature Commission, Taiwan Provincial, Government ROC, p. 424 (in Chinese).

Lin, Y.N., 2005. Surface deformation and seismogenic structure model of the 1935 Hsinchu-Taichung Earthquake $\left(\mathrm{M}_{\mathrm{GR}}=7.1\right)$, in Miaoli, northwestern Taiwan. MS thesis, Institute of Geosciences, National Taiwan University, 82pp.

Meng, C.Y., 1963. San-I overthrust. Petroleum Geology of Taiwan 2, 1-20.

Namson, J., 1981. Structure of the western foothills belt, Miaoli-Hsinchu area, Taiwan: (I) Southern part. Petroleum Geology of Taiwan 18, 31-51.

Namson, J., 1982. Structure of the western foothills belt, Miaoli-Hsinchu area, Taiwan: (II) Central part. Petroleum Geology of Taiwan 19, 51-76.

Rubin, C., Sieh, K., Chen, Y.G., Lee, J.C., Chu, H.T., Yeats, R., Mueller, K., Chan, Y.C., 2001. Post-earthquake response, 1999 Chi-Chi earthquake: evidence for past earthquakes, EOS. Transactions AGU 82 (47), 565.

Ota, Y., Lin, Y.N., Chen, Y.G., Chang, H.C., Hung, J.H., 2006. Newly found Tunglo Active Fault System in the fold and thrust belt in north- western Taiwan deduced from deformed terraces. Tectonophysics 317, 305-323.

Otuka, Y. (1936) The earthquake of central Taiwan (Formosa), April 21, 1935, and earthquake faults. Bulletin of the Earthquake Research Institute, Suppl. vol. 3, 22-74 (in Japanese).

Shih, T.T., Chang, R.C., Yang, G.S., 1983. Active faults and geomorphic surfaces of the Houli tableland. Bulletin of the Geomorphical Society of China 11, 46-55.

Shih, T.T., Teng, K.H., Chang, R.C., Shih, C.T., Yang, G.S., Hsu, M.Y., 1984. Geomorphological study on active structures, western and southern Taiwan. Geographical Research Report 10, 49-94. Department of Geography, National Taiwan Normal University.

Shyu, J.B.H., Sieh, K., Chen, Y.G., Liu, C.S., 2004. The neotectonic architecture of Taiwan and its implications for future large earthquakes. Journal of Geophysical Research 110, B08402. doi:10.1029/ 2004JB00325.

Suppe, J., 1983. Geometry and kinematics of fault-bend folding. American Journal of Sciences 283, 684-721.

Suppe, J., Namson, J., 1979. Fault-bend origin of frontal folds of the western Taiwan fold-and-thrust belt. Petroleum Geology of Taiwan 16, 118.

Teng, L.S., 1990. Geotectonic evolution of late Cenozoic arc-continent collision in Taiwan. Tectonophysics 183, 57-76.

Yang, G.S. (1986) A geomorphological study of active faults in Taiwan: Especially on the relation between active faults and geomorphic surfaces, Ph.D. thesis, Chinese Culture University, 178pp.

Yang, K.M., Huang, S.T., Ting, H.H., Wu, J.C., Lin, Y.N., Lee, M., 2004. The role of normal faulting in the most tectonics of western Taiwan. Abstract of International Conference in Commemoration of 5th Anniversary of the 1999 Chi Chi Earthquake, Taiwan, pp. 23-24. 